\title{
Response of wild-type mutants of Vibrio cholerae 01 possessing different combinations of virulence genes in the ligated rabbit ileal loop and in Ussing chambers: evidence for the presence of additional secretogen
}

\author{
HEMANTA KOLEY, RUPAK MITRA, ARNAB BASU, ASISH K. MUKHOPADHYAY, P. K. SAHA, B. S. \\ RAMAKRISHNA*, SELVI KRISHNAN*, YOSHIFUMI TAKEDA $\dagger$ and G. BALAKRISH NAIR
}

National Institute of Cholera and Enteric Diseases, Beliaghata, Calcutta 700 010, India, *Department of Gastrointestinal Sciences, Christian Medical College and Hospital, Vellore 632 004, India and †Research Institute, International Medical Center of Japan, Shinjuku-ku, Tokyo 162, Japan

\begin{abstract}
Five wild-type mutant strains of Vibrio cholerae serogroup 01 that lacked the CTX virulence cassette, or contained a natural deletion of a virulence gene within the CTX virulence cassette, or possessed an additional virulence gene, along with a prototype toxigenic strain representing the EI Tor classical biotypes were examined by in-vivo and in-vitro methods to determine their enterotoxic potential. The ability of whole cells and culture supernates of the strains to cause fluid accumulation in the rabbit ileal loop model revealed a pattern consistent with the presence of the various virulence gene(s), with those possessing the intact CTX virulence cassette being the most secretogenic. Culture supernates of strains without the CTX virulence cassette or the strain with an incomplete cassette were also able to evoke mild to moderate fluid accumulation in the rabbit ileal loop. Of the various media used, AKI and brain heart infusion broth appeared to support the production of a hitherto unknown secretogenic factor, because culture supernates of the non-toxigenic $V$. cholerae 01 strains showed higher fluid accumulation ratios when grown in these media than in the others. To confirm that the fluid accumulation elicited by these strains in the ileal loop was due to enterotoxin activity, the effect of supernate of the strains was examined in rabbit small intestine mounted on Ussing chambers. Increases in short circuit current and tissue conductance, as compared with the medium control, were observed even with the strains that did not possess the CTX virulence cassette, confirming their ability to disrupt the function of intestinal tissue. From these studies, it was concluded that strains of $V$. cholerae 01 devoid of the CTX virulence cassette were still able to elicit a secretory response in the ileal loop and displayed enterotoxic activity in an in-vitro experimental model.
\end{abstract}

\section{Introduction}

Cholera, an acute disease characterised by copious uncontrolled purging of 'rice-water' stools leading to severe electrolyte depletion, dehydration, acidosis, shock and, if left untreated, to death, is caused by Vibrio cholerae belonging to either the $\mathrm{O} 1$ or $\mathrm{O} 139$ serogroups $[1,2]$. The clinical state of cholera is

Received 27 Nov. 1997; revised version accepted 6 May 1998.

Corresponding author: Dr G. Balakrish Nair. principally attributed to an oligomeric protein known as cholera toxin (CT) that activates adenylate cyclase, resulting in increased levels of cyclic AMP leading to hypersecretion of salt and water [3]. A mélange of other putative toxins produced by $V$. cholerae, such as the E1 Tor haemolysin $[4,5]$, zona occludens toxin (Zot) [6] and accessory cholera toxin (Ace) [7] are believed to exacerbate the fluid secretion process and thereby contribute to the disease, but in ways not precisely discerned as yet. A dynamic $4.5-\mathrm{kb}$ core region [8], termed the CTX virulence cassette [7], has now been identified in toxigenic $V$. cholerae $\mathrm{O} 1$ and O139 strains that, apart from carrying the CT genes $(\operatorname{ctx} A B)$, also carries the gene encoding a pilin-like 
intestinal colonisation factor [9], the gene encoding Zot [10] and the gene encoding Ace [7]. Most recent studies show that the structural genes for CT reside on the genome of a filamentous, lysogenic phage called $\mathrm{CTX} \phi[11]$.

The development of a safe, attenuated, live oral recombinant cholera vaccine has been plagued with the problem of reactogenicity of the vaccine strains manifested as residual diarrhoea. Various attenuated $V$. cholerae $\mathrm{Ol}$ recombinant vaccine candidates have been constructed over the past decade. These strains were clearly incapable of causing severe diarrhoea, but were still capable of inducing unacceptable levels of mild diarrhoea in human volunteer studies $[12,13]$. However, it must be mentioned that one recombinant $V$. cholerae $\mathrm{O} 1$ vaccine strain (CVD103.HgR) derived from the classical Inaba strain $569 \mathrm{~B}$ has proved to be well tolerated and immunogenic in extensive trials in different countries [14]. A recent study examined a large collection of strains of $V$. cholerae of diverse origins with a battery of DNA probes specific for CT, Zot, Ace and E1 Tor haemolysin and was able to detect strains of $V$. cholerae $\mathrm{O} 1$ with natural deletion of the $\operatorname{ctxA}$ gene within the CTX virulence cassette [15]. The availability of these wild-type mutants of $V$. cholerae $\mathrm{Ol}$ provided the impetus for the present study. The objective was to assess the enterotoxicity of these wild-type mutants to see whether these strains were capable of disrupting the function of intestinal tissue and thereby determine if other secretogens are involved in the pathogenesis of $V$. cholerae O1. Such a study could provide useful insights into the well-noted reactogenicity of vaccine strains of $V$. cholerae $\mathrm{O} 1$ lacking known toxins, including CT.

\section{Materials and methods}

\section{Bacterial strains}

Seven strains of $V$. cholerae O1 (GP5, GP6, GP12, GP71, GP156, V96 and VC20) were selected from our culture collection and used in this study. The choice of strains was dictated by the results of previous studies $[15,16]$ and the strains were selected to represent as many combinations as possible of the virulence genes as shown in Table 1. All the strains were biochemically characterised, including determination of polymyxin B sensitivity by methods described previously [17]. The strains were maintained as stabs in nutrient agar at room temperature and kept in the dark.

\section{Detection of CT production}

The test strains were grown in yeast extract peptone (YEP) [18] with shaking $(120 \mathrm{rpm})$ at $37^{\circ} \mathrm{C}$. The culture supernates of the $V$. cholerae $\mathrm{Ol}$ strains were examined for the presence of CT by a highly sensitive bead-ELISA [19]. Various dilutions of purified CT (Sigma) and uninoculated medium (negative control) were run concurrently when the culture supernates of the test strains were assayed by the bead-ELISA.

\section{Production of haemolysin}

Brain Heart Infusion Broth (BHIB; Difco Laboratories, MI, USA) with $\mathrm{NaCl} 0.5 \%$ was used to grow the strains for detemination of E1 Tor haemolysin production [20]. The strains were grown in $2 \mathrm{ml}$ of $\mathrm{BHIB}$ in test tubes $(10 \times 13 \mathrm{~cm})$ and also in $50 \mathrm{ml}$ of BHIB contained in 250-ml Erlenmeyer flasks. Washed rabbit erythrocytes diluted to a final concentration of $1 \%$ in $10 \mathrm{mM}$ phosphate buffer ( $\mathrm{pH} 7.0$ ) containing $\mathrm{NaCl}$ $1.3 \%$ were mixed with an equal volume of the culture supernate and incubated at $37^{\circ} \mathrm{C}$ for $1 \mathrm{~h}$. The mixture was then centrifuged at $1000 \mathrm{~g}$ for $5 \mathrm{~min}$ and the amount of released haemoglobin in the supernate was measured spectrophotometrically at $540 \mathrm{~nm}$.

\section{Polymerase chain reaction assay}

A multiplex polymerase chain reaction (PCR)-based assay was used to determine the presence of $c t x A$ (encoding the enzymic subunit of $\mathrm{CT}$ ) and tep $A$ (encoding the major structural subunit of TCP), while a single-format PCR assay was used for toxR (encoding the transcription activator ToxR), zot (encoding Zot) and ace (encoding Ace). Primer pairs were used to detect the following: a 301-bp fragment of $c t x A$ [21], a 471-bp fragment of E1 Tor variant of tcpA, a 671-bp fragment of classical variant of tcpA [22], a 990-bp fragment of toxR [23], a 243-bp fragment of zot and a 284-bp fragment of ace [24].

The following were added to each $100 \mu \mathrm{l}$ of PCR mixture: $10 \mu 1$ of $10 \times$ PCR buffer ( $100 \mathrm{mM}$ TAPS, pH $8.8 ; 500 \mathrm{mM} \mathrm{KCl} ; 15 \mathrm{mM} \mathrm{MgCl}_{2}$ and gelatin $0.1 \%$ ), $2 \mu \mathrm{l}$ each of $2.5 \mathrm{mM}$ dATP, dGTP, dCTP and dTTP, $100 \mathrm{pmol}$ each of the primers and $2 \mathrm{U}$ of Taq DNA polymerase (Takara Shuzo Co. Ltd, Japan). PCR was carried out in $0.5-\mathrm{ml}$ thin-walled PCR tubes (Midwest, USA), with $42 \mu \mathrm{l}$ of the PCR mixture described above and $8 \mu \mathrm{l}$ of a Luria broth culture of the test strain, overlaid with mineral oil, heated at $94^{\circ} \mathrm{C}$ for $5 \mathrm{~min}$ and processed in a DNA thermal cycler (Biometra, Göttingen, Germany). PCR amplification was performed for 30 cycles and the cycling conditions for $c t x A, \operatorname{tcp} A$ and toxR were: denaturation at $94^{\circ} \mathrm{C}$ for $1 \mathrm{~min}$, annealing at $60^{\circ} \mathrm{C}$ for $1.5 \mathrm{~min}$ and extension at $72^{\circ} \mathrm{C}$ for $1.5 \mathrm{~min}$; for zot and ace the time for annealing and extension was $1 \mathrm{~min}$ each. A reagent blank (containing all the components of the reaction mixture and Luria broth instead of broth containing template DNA) and two $V$. cholerae $\mathrm{O} 1$ strains - one belonging to the E1 Tor biotype (VC20) and the other to the classical biotype (569B) - from our culture collection were run as controls. Amplified products from the PCR were electrophoresed on agarose $1.5 \%$ gels and were stained with ethidium bromide. $\phi \times 174-$ 
Hae III (Takara Shuzo Co. Ltd) mol. wt marker was run concurrently.

\section{Rabbit ileal loop assay}

Challenge doses were prepared by growing the bacterial strains to mid-exponential phase in Tryptic Soy Broth (Difco) at $37^{\circ} \mathrm{C}$ followed by low speed centrifugation and resuspension to $c .10^{8}$ bacteria $/ \mathrm{ml}$ in phosphate-buffered saline (PBS, $\mathrm{pH} \mathrm{7.2)} \mathrm{for} \mathrm{intro-}$ duction into the ligated loops. Culture filtrates of the test strains, grown in various broths - i.e., AKI [25], YEP [18], BHIB, casamino acid-Yeast Extract medium with lincomycin $90 \mathrm{mg} / \mathrm{L}$ (CAYE-L) and syncase medium [26] - were obtained from the supernate which remained after centrifugation of the culture at $6000 \mathrm{~g}$ for $20 \mathrm{~min}$ in the cold.

Surgical procedures for the ligated intestinal loop test according to the method described by De and Chatterjee [27] were carried out on outbred New Zealand White rabbits of either sex weighing $c .2 .0-2.5 \mathrm{~kg}$. Briefly, laparotomy was performed on animals anaesthetised by intramuscular injection of ketamine ( $35 \mathrm{mg} / \mathrm{kg}$ body weight) and xylazine $(5 \mathrm{mg} / \mathrm{kg}$ body weight). The small intestine was withdrawn and ligated at a distance of $c .10 \mathrm{~cm}$ from the ileocaecal region. Eight intestinal loops of $6-10 \mathrm{~cm}$, separated by uninoculated segments of $1-2 \mathrm{~cm}$, were made in each animal. Test loops were inoculated with 1-ml volumes of bacterial suspensions or culture supernates. Negative control loops received either PBS alone or the uninoculated medium, while the positive control loop received bacterial suspension of the prototype $V$. cholerae $\mathrm{Ol}$ biotype E1 Tor strain (VC20). Loops were replaced in the peritoneal cavity in the original position and the peritoneum was closed. After 18$20 \mathrm{~h}$, the animal was killed with sodium pentobarbital and the abdomen was re-opened. The loops were taken out and the length of each loop in $\mathrm{cm}$ and the volume of the accumulated fluid in $\mathrm{ml}$ were measured. The extent of the fluid accumulation (FA) was expressed as the FA ratio.

\section{Ussing chamber experiments}

The test strains were cultured in $50 \mathrm{ml}$ of AKI, YEP, BHIB, CAYE-L and syncase medium and incubated at $37^{\circ} \mathrm{C}$ with shaking $(200 \mathrm{rpm})$. The cell-free culture filtrate obtained by centrifugation at $5000 \mathrm{~g}$ for $20 \mathrm{~min}$ and passage through a $0.22 \mu \mathrm{m}$ pore size disposable filter was lyophilised and resuspended in $15 \mathrm{ml}$ of sterile double-distilled water. Ussing chamber experiments were performed with segments of small intestine from male adult New Zealand white rabbits (body weight $1.5-2.5 \mathrm{~kg}$ ). Rabbits were anaesthetised by intramuscular injection of ketamine $(35 \mathrm{mg} / \mathrm{kg}$ of body weight) and xylazine (5 mg/ $\mathrm{kg}$ of body weight) and killed by air embolism. A $15-\mathrm{cm}$ segment of distal ileum was teased loose from the mesentery, flushed free of intestinal contents with Ringer's solution ( $115 \mathrm{mM} \mathrm{NaCl}, 25 \mathrm{mM} \mathrm{NaHCO}, 2.5 \mathrm{mM} \mathrm{K}_{2} \mathrm{HPO}_{4}$, $0.4 \mathrm{mM} \quad \mathrm{KH}_{2} \mathrm{PO}_{4}, 1.2 \mathrm{mM} \quad \mathrm{MgCl}_{2}, 1.2 \mathrm{mM} \mathrm{CaCl}_{2}$ ), opened along the mesenteric border, and stripped of muscular and serosal layers. Sheets of mucosa were then mounted on prongs in lucite Ussing chambers with an aperture of $1.13 \mathrm{~cm}^{2}$ and bathed by freshly prepared Ringer's solution which was maintained at $37^{\circ} \mathrm{C}$ with water-jacketed reservoirs connected to a constant temperature circulating pump and gassed with $\mathrm{O}_{2} \quad 95 \%$ and $\mathrm{CO}_{2} 5 \%$. The potential difference and short circuit current (Isc) were measured. The potential difference was allowed to reach a steady state. A $400 \mu \mathrm{l}$ volume of test supernate was added to either side of the mucosa. The changes in Isc were recorded at 5-min intervals for the first reading and then at 15min intervals up to $110 \mathrm{~min}$. The non-parametric Kruskal-Walli's test was applied to determine the statistical difference in variation in conductance of culture supernate of strains grown in different media.

\section{Results}

\section{Phenotypic and genotypic traits of the strains}

Of the seven strains included in this study, five were wild-type mutants that lacked all the virulence genes in the CTX virulence cassette (GP5, GP6, V96), or contained internal deletion within the CTX virulence cassette (GP71), or, in addition to an intact CTX virulence cassette, also carried sto and produced NAGST-like toxin (GP156) $[16,28]$ as shown in Table 1. The prototype $V$. cholerae O1 strain of the El Tor biotype was represented by strain VC20 [29] and the classical biotype was represented by strain GP12, and these were used as the positive controls. Strains GP156, GP12 and VC20 produced CT when examined by the bead-ELISA (Table 1) and yielded the 301-bp ctxA amplicon; the other strains were negative for the factors in both assays. All the strains yielded the 990-bp fragment of toxR amplicon whereas only four of the seven strains (GP12, GP71, GP156, and VC20) yielded the 243-bp zot amplicon and 284-bp ace amplicon. Apart from strain GP6, all strains yielded the tcpA amplicon. In five strains (GP5, V96, GP71, GP156 and VC20), the tcpA amplicon was $471 \mathrm{bp}$, which was consistent with the E1 Tor variant of the $t c p A$ gene. The size of the $t c p A$ amplicon of strain GP12 was $621 \mathrm{bp}$, suggesting that the strain belonged to the classical biotype. Also, strain GP12 was sensitive to polymyxin B, a trait which is consistent with the classical biotype. All the strains carried the structural gene $(h l y A)$ for the E1 Tor haemolysin; only strains GP71 and GP156 produced E1 Tor haemolysin when grown in $50 \mathrm{ml}$ cultures, but none of these strains produced the haemolysin when grown in 2-ml cultures. Strain VC20, the prototype $V$. cholerae $\mathrm{Ol}$ strain of E1 Tor biotype, is genotypically hlyA-positive, but shows no haemolytic activity in vitro and this is consistent 
Table 1. Genotypic and phenotypic traits of the $V$. cholerae $\mathrm{Ol}$ strains examined in this study

\begin{tabular}{|c|c|c|c|c|c|c|c|c|c|c|c|c|}
\hline \multirow{4}{*}{$\begin{array}{l}\text { Strain } \\
\text { no. }\end{array}$} & \multirow{4}{*}{$\begin{array}{l}\text { Place of } \\
\text { isolation }\end{array}$} & \multirow{4}{*}{$\begin{array}{l}\text { Year of } \\
\text { isolation }\end{array}$} & \multirow[b]{4}{*}{ Serotype } & \multicolumn{8}{|c|}{ Genotype } & \multirow{4}{*}{$\begin{array}{l}\text { CT production } \\
(\mathrm{ng} / \mathrm{ml})\end{array}$} \\
\hline & & & & \multicolumn{7}{|c|}{ Presence of virulence genes by PCR } & \multirow{3}{*}{$\begin{array}{c}\text { Heat-stable } \\
\text { enterotoxin gene } \\
(\text { sto })^{*}\end{array}$} & \\
\hline & & & & \multirow[b]{2}{*}{$h l y A$} & \multirow[b]{2}{*}{ tox $R$} & \multirow[b]{2}{*}{$c t x A$} & \multirow[b]{2}{*}{$z o t$} & \multirow[b]{2}{*}{ ace } & \multicolumn{2}{|c|}{$t c p A$} & & \\
\hline & & & & & & & & & E1 Tor & Classical & & \\
\hline GP5 & Macao & 1970 & Inaba & + & + & - & - & - & + & - & - & - \\
\hline GP6 & Macao & 1970 & Inaba & + & + & - & - & - & - & - & - & - \\
\hline V96 & India & 1990 & Ogawa & + & + & - & - & - & + & - & - & - \\
\hline GP12 & India & 1971 & Ogawa & + & + & + & + & + & - & + & - & ++ \\
\hline GP71 & India & 1974 & Ogawa & + & + & - & + & + & + & - & - & - \\
\hline GP156 & Australia & 1979 & Inaba & + & + & + & + & + & + & - & + & ++ \\
\hline VC20 & $\begin{array}{l}\text { Calcutta } \\
\text { (India) }\end{array}$ & 1992 & Ogawa & + & + & + & + & + & + & - & - & ++ \\
\hline
\end{tabular}

${ }^{*}$ Data on sto from references $[16,28]$.

with the characteristics of recent El Tor strains which are non-haemolytic or weakly haemolytic.

\section{Enterotoxicity of whole cells examined by rabbit ileal loop test}

Of the whole cell preparations of the seven strains examined, four (GP5, GP6, GP71 and V96) were nonsecretogenic or the amount of fluid accumulated in the test loops of rabbits was negligible; one strain (GP12) was moderately secretogenic and two (GP156 and the positive control strain VC20) induced fluid accumulation consistent with that of a fully toxigenic strain of $V$. cholerae (Table 2).

\section{Enterotoxigenicity of strains grown in different broths in the rabbit ileal loop test}

Culture supernates of the test strains grown in five different broth media showed variations in their ability to induce fluid accumulation in the ligated loop between media, but followed a general overall pattern that reflected the trend shown with whole cells (Table 2). Again, the secretogenicity of the test strains in ascending order was V96, GP71, GP5, GP6, GP12, VC20 and GP156. A revealing finding was that, of the media used, AKI and BHIB appeared to support the production of an unknown secretogenic factor, because all the test strains showed higher FA ratios than with other media. This included strains GP5, GP6 and V96, which by definition are non-toxigenic $V$. cholerae $\mathrm{Ol}$ and should have been benign in the rabbit ligated loop.

\section{Enterotoxigenicity of strains in Ussing chambers}

Culture supernate of strains of $V$. cholerae $\mathrm{O} 1$ grown in different media were added to rabbit ileal tissue mounted between lucite chambers maintained under conditions of ionic, osmotic and electrical equilibrium to investigate whether the supernates induced an increase in Isc. A general pattern was observed, with the fully toxigenic strain $\mathrm{VC} 20$ inducing the largest increase in Isc irrespective of the medium used (Table 3). Interestingly, the other fully toxigenic strain (GP156) did not induce changes in Isc consistent with that of the presence of CT and NAG-ST in all media. In contrast, strain GP12 - which is a fully toxigenic classical strain - evoked higher Isc changes than strain GP156, and was more or less similar to strain VC20 in this respect. The broth medium used appeared to effect changes in Isc with strain V96, the non-toxigenic strain, showing fairly high Isc changes in most media except syncase. Again, compared with the toxigenic strains, the non-toxigenic strains GP5 and GP6 showed

Table 2. Fluid accumulating ability of the strains of $V$. cholerae $\mathrm{O} 1$ in rabbit ligated ileal loop

\begin{tabular}{lcccccc}
\hline & \multicolumn{5}{c}{ Fluid accumulation ratio $(\mathrm{ml} / \mathrm{cm})$} \\
\cline { 3 - 7 } & & \multicolumn{5}{c}{ Supernate of strain grown in ${ }^{\dagger}$} \\
\cline { 3 - 7 } Strain no. & Whole cells & AKI & YEP & BHIB & CAYE-L & syncase \\
\hline GP5 & 0 & 0.49 & 0.23 & 0.41 & 0.29 & 0.25 \\
GP6 & $0.10(0.18)$ & 0.55 & 0.37 & 0.67 & 0.22 & 0.13 \\
V96 & $0.19(0.23)$ & 0.31 & 0.07 & 0.53 & 0.13 & 0.26 \\
GP12 & $0.41(0.14)$ & 1.16 & 1.21 & 0.96 & 1.10 & 0.85 \\
GP71 & 0 & 0.47 & 0.11 & 0.60 & 0.11 & 0.22 \\
GP156 & $1.13(0.19)$ & 1.18 & 0.85 & 1.33 & 1.48 & 1.23 \\
VC20 & $1.04(0.18)$ & 1.12 & 1.17 & 1.1 & 1.42 & 1.26 \\
Medium & $\cdots$ & 0.09 & 0.25 & 0.26 & 0 & 0.13 \\
\hline
\end{tabular}

*Values are mean (SE) of experiments performed in five rabbits.

${ }^{\dagger}$ Values are mean of experiments performed in two rabbits. 
Table 3. Variation in Isc in Ussing chambers after addition of $400 \mu \mathrm{l}$ of culture supernates of different wild-type $V$. cholerae $\mathrm{O} 1$ strains grown in AKI, YEP, BHIB, CAYE-L and syncase to both mucosal and serosal sides of rabbit intestinal tissue recorded after $35 \mathrm{~min}$ and $110 \mathrm{~min}$

\begin{tabular}{|c|c|c|c|c|c|c|c|c|c|c|}
\hline \multirow{3}{*}{$\begin{array}{l}\text { Strain } \\
\text { no. }\end{array}$} & \multicolumn{10}{|c|}{ Isc } \\
\hline & \multicolumn{2}{|c|}{ AKI } & \multicolumn{2}{|c|}{ YEP } & \multicolumn{2}{|c|}{ BHIB } & \multicolumn{2}{|c|}{ CAYE-L } & \multicolumn{2}{|c|}{ Syncase } \\
\hline & 35 & 110 & 35 & 110 & 35 & 110 & 35 & 110 & 35 & 110 \\
\hline GP5 & $22(12)$ & $33 \quad(8)$ & $31(21)$ & $44 \quad(4)$ & $32(23)$ & $54(11)$ & $42(20)$ & $46(13)$ & $34 \quad(9)$ & $48(13)$ \\
\hline GP6 & $48(17)$ & 49 (12) & 47 (17) & 56 (3) & 49 (29) & $48(16)$ & $13(9)$ & 27 (12) & $45(31)$ & $38(21)$ \\
\hline GP12 & $52(15)$ & 76 (11) & 33 (15) & $67 \quad(0)$ & 29 (17) & 79 (24) & 32 (14) & 49 (9) & 63 (18) & $75(18)$ \\
\hline GP71 & 19 (13) & 39 (9) & $38(16)$ & $56 \quad$ (4) & $27(26)$ & $60(28)$ & $33(21)$ & $55(26)$ & 34 (12) & 43 (9) \\
\hline GP156 & $20 \quad(2)$ & 56 (2) & $45(24)$ & $81(26)$ & 11 (3) & $49 \quad(4)$ & 48 (16) & $85(28)$ & $35(16)$ & $71(22)$ \\
\hline V96 & $35(10)$ & $63(6)$ & $23(13)$ & $52(10)$ & 31 (15) & $69 \quad(7)$ & 30 (13) & 57 (19) & 21 & $12(1)$ \\
\hline $\mathrm{VC} 20$ & 39 (23) & $80(15)$ & $22(12)$ & 91 (23) & $43(29)$ & $75 \quad(7)$ & $56(37)$ & $90(30)$ & 36 (13) & $84(25)$ \\
\hline Medium & $14(6)$ & $17(5)$ & 11 (6) & $21 \quad(5)$ & 23 (4) & 11 & $5 \quad(8)$ & $5 \quad(7)$ & 6 (3) & $2(0)$ \\
\hline
\end{tabular}

Values are mean (SEM) of four experiments.

lower changes in Isc over a period of time. Medium again played a role in changes in Isc with strain GP6 evoking hardly any change in Isc when grown in CAYE-L, but showing substantial changes in Isc, compared with the medium control, in all the other media used (Table 3).

The conductance values of culture supernates of different strains grown in different media are presented in Table 4. Conductance of a tissue is a useful index of the leakiness of the tissue - increased conductance indicating disruption of function of the tight junctions. Conductance was again influenced by the medium used and the least changes in conductance were observed in YEP and BHIB. For example, with the non-toxigenic strains (GP5, GP6, V96), increases in conductance were observed when they were grown in AKI medium as compared with YEP and BHIB. In CAYE-L and syncase media, the two non-toxigenic strains (GP5, GP6) did not evoke changes in conductance. This pattern in the changes of conductance was also consistent with all the other strains. However, the variation in conductance of the various strains grown in different media was not statistically significant.

\section{Discussion}

After more than 17 years of elegant and vigorous research on the development of oral recombinant vaccine strains for cholera, it has become clear that the pathogenesis of cholera is not as straightforward as previously perceived. From the human volunteer studies with recombinant oral cholera vaccine strains [12], the involvement of another toxin in addition to those currently recognised or the process of colonisation, or both, have been attributed to be the cause of the mild to moderate residual diarrhoea $[1,12]$. Interest in the ancillary secretogenic factors was further stimulated by the clinical observation of cholera-like diarrhoea caused by $V$. cholerae belonging to the non-O1 nonO139 serogroups. Although the percentage of such patients hospitalised at the Infectious Diseases Hospital in Calcutta is usually $<4.9 \%$ [30], it presented an enigma as to how strains of $V$. cholerae devoid of the CTX virulence cassette were still able to cause a clinical condition very similar to cholera. To add to the mystery, non-toxigenic strains of $V$. cholerae $\mathrm{Ol}$ associated with a cluster of cases of cholera were encountered recently in southern India [31]. All these events led to the design of the present study, to answer the basic question as to whether $V$. cholerae devoid of the CTX virulence cassette is enterotoxigenic.

Strains GP5, GP6 and V96 represented the nontoxigenic strains of $V$. cholerae $\mathrm{O} 1$ in this study. Genotypically, the three strains were very similar, except that strain GP6 did not possess tcpA. Whole cells of the three non-toxigenic strains were inert in the rabbit ileal loop assay, but culture filtrate of the three strains showed enterotoxic activity, especially

Table 4. Variations in conductance in Ussing chambers induced by culture supernates of the various $V$. cholerae $\mathrm{O} 1$ strains recorded after $95 \mathrm{~min}$

\begin{tabular}{|c|c|c|c|c|c|c|c|c|}
\hline \multirow[b]{2}{*}{ Medium } & \multicolumn{8}{|c|}{ Conductance $\left(\mathrm{Ohm}^{-1}\right)^{*}$} \\
\hline & GP5 & GP6 & V96 & GP12 & GP71 & GP156 & VC20 & $\begin{array}{c}\text { Medium } \\
\text { control }\end{array}$ \\
\hline $\begin{array}{l}\text { AKI } \\
\text { YEP } \\
\text { BHIB } \\
\text { CAYE-L } \\
\text { Syncase }\end{array}$ & $\begin{array}{l}66 \pm 5 \\
31 \pm 6 \\
36 \pm 5 \\
48 \pm 21 \\
45 \pm 5\end{array}$ & $\begin{array}{l}83 \pm 33 \\
36 \pm 1 \\
56 \pm 17 \\
30 \pm 6 \\
45 \pm 20\end{array}$ & $\begin{array}{l}62 \pm 14 \\
45 \pm 15 \\
47 \pm 8 \\
35 \pm 14 \\
59 \pm 18\end{array}$ & $\begin{array}{l}58 \pm 0 \\
50 \pm 0 \\
45 \pm 8 \\
30 \pm 12 \\
60 \pm 15\end{array}$ & $\begin{array}{l}50 \pm 8 \\
35 \pm 0 \\
60 \pm 5 \\
25 \pm 8 \\
48 \pm 5\end{array}$ & $\begin{array}{l}50 \pm 8 \\
44 \pm 0 \\
32 \pm 6 \\
50 \pm 14 \\
47 \pm 18\end{array}$ & $\begin{array}{l}63 \pm 24 \\
39 \pm 3 \\
45 \pm 11 \\
56 \pm 16 \\
76 \pm 15\end{array}$ & $\begin{array}{l}37 \pm 16 \\
31 \pm 8 \\
42 \pm 3 \\
34 \pm 21 \\
40 \pm 12\end{array}$ \\
\hline
\end{tabular}

${ }^{*}$ Values are mean $\pm \mathrm{SE}$ of four experiments. 
when grown in AKI and BHIB. Likewise, a mediumdependent increase in Isc and tissue conductance were observed in the Ussing chambers experiment. Taken together, it could be summarised that the three nontoxigenic strains possessed a medium-dependent enterotoxic factor. It appears that some component in $\mathrm{AKI}$ and BHIB triggers the production of the elusive secretogen. It is pertinent to mention here that certain clinical strains of $V$. cholerae non-O1 produced an extracellular factor when grown in AKI medium that evoked a rapid and dramatic cytotoxic response which manifested as cell rounding of $\mathrm{CHO}$ and HeLa cells without accompanying membrane damage [32]. The purified cytotoxin has shown impressive enterotoxic activity in the ligated ileal loop and is reportedly present in 81.3 and $100 \%$ of the toxigenic and nontoxigenic strains, respectively, of $V$. cholerae $\mathrm{O} 1$ [33].

The magnitude of difference in Isc of the strains grown in different media was more or less similar in the Ussing chambers, although strains grown in AKI and BHIB showed greater fluid accumulation in the rabbit ileal loop test. This appears to be contradictory, but there could be a reason for this. The fluid accumulation in rabbit ileal loop is the end-product of the manifestation of an enterotoxic factor, while changes in Isc reflect either ion secretion (increase in Isc and potential difference) or perturbation in the paracellular junction (increase in tissue conductance) of ileal tissue. In other words, the results of the Ussing chamber experiments give an idea of the possible mechanism involved in inducing the secretogenic effect. In this case, it appears that the increased fluid accumulation in rabbit ileal loop observed with strains grown in AKI and BHIB may not be caused by an increase in Isc, but by a mechanism other than this which needs to be investigated.

The inertness of the whole cells of non-toxigenic $V$. cholerae $\mathrm{Ol}$ in the rabbit ileal loop suggests that these strains possess an enterotoxic potential, but need appropriate external signals to stimulate production of the factor. It is now known that various environmental signals such as osmolarity, $\mathrm{pH}$, temperature, amino acids, $\mathrm{CO}_{2}$ and iron control the expression of co-ordinately regulated virulence determinants in $V$. cholerae and other bacteria (reviewed by Mekalanos) [34]. An alternative explanation is that the nontoxigenic strains probably did not colonise and grow well in the rabbit ileal loops as compared with their toxigenic counterparts. Previous studies have documented that in-vivo growth of $V$. cholerae is greater for fully toxigenic strains than for poorly toxinogenic strains $[35,36,37]$. It has been suggested that intestinal fluid secretion stimulated by CT creates an improved environment for bacterial multiplication [38]. Evidently, the supernates of non-toxigenic strains of $V$. cholerae $\mathrm{O} 1$ examined in this study contain material that manifests enterotoxic activity in rabbit ileal loops and in Ussing chambers when grown in an appropriate medium. We are unable to explain why whole cells of GP12 (the classical biotype strain) with an intact CTX virulence cassette were unable to evoke as much fluid accumulation as the prototype E1 Tor biotype strain, although culture supernate of this strain yielded data consistent with that of a toxigenic strain in rabbit ileal loops and in Ussing chambers.

Strain GP71 was chosen to assess the contributory effect of the natural deletion of the $c t x A$ gene located within the CTX virulence cassette. The $\operatorname{ctx} A$ gene was clearly the most important constituent gene in the CTX virulence cassette in terms of evoking a secretory response. Strain GP71 was not secretogenic when whole cells were introduced in the ileal loop, but was secretogenic when supernates of the strain grown in broth were introduced into the ileal loop. Although these results appear conflicting, it is possible that in the broth some environmental signal may have triggered the production of an enterotoxic factor which did not happen when the cells were introduced directly into the rabbit ileal loop.

The award of a Senior Research Fellowship to P. K. S. from the Council of Scientific and Industrial Research (CSIR), New Delhi, India is gratefully acknowledged. We thank $\mathrm{Dr} \mathrm{A}$. C. Ghose, Department of Microbiology, Bose Institute, Calcutta, India for providing the toxR primers. We also thank Dr B. Manna, Senior Research Officer, for statistical analysis of the data. This work was partially supported by grant $\mathrm{BT} / \mathrm{TH} / 9 / 63 / 91$ from the Department of Biotechnology, New Delhi, India.

\section{References}

1. Kaper JB, Morris JG, Levine MM. Cholera. Clin Microbiol Rev 1995; 8: 48-86.

2. Nair GB, Albert MJ, Shimada T, Takeda Y. Vibrio cholerae 0139 Bengal, the new serogroup causing cholera. Rev Med Microbiol 1996; 7: 43-51.

3. Field M. Intestinal secretion: effect of cyclic AMP and its role in cholera. $N$ Engl J Med 1971; 284: 1137-1144.

4. Alm RA, Mayrhofer G, Kotlarski I, Manning PA. Aminoterminal domain of the E1 Tor haemolysin of Vibrio cholerae $\mathrm{Ol}$ is expressed in classical strains and is cytotoxic. Vaccine 1991; 9: 588-594.

5. Ichinose Y, Yamamoto K, Nakasone $\mathrm{N}$ et al. Enterotoxicity of El Tor-like haemolysin of non-O1 Vibrio cholerae. Infect Immun 1987; 55: 1090-1093.

6. Fasano A, Baudry B, Pumplin DW et al. Vibrio cholerae produces a second enterotoxin which affects intestinal tight junctions. Proc Natl Acad Sci USA 1991; 88: 5242-5246.

7. Trucksis M, Galen JE, Michalski J, Fasano A, Kaper JB. Accessory cholera enterotoxin (Ace), the third toxin of a Vibrio cholerae virulence cassette. Proc Natl Acad Sci USA 1993; 90: 5267-5271.

8. Goldberg I, Mekalanos JJ. Effect of a recA mutation on cholera toxin gene amplification and deletion events. J Bacteriol 1986; 165: $723-731$.

9. Pearson GDN, Woods A, Chiang SL, Mekalanos JJ. CTX genetic element encodes a site-specific recombination system and an intestinal colonization factor. Proc Natl Acad Sci USA 1993; 90: 3750-3754.

10. Baudry B, Fasano A, Ketley J, Kaper JB. Cloning of a gene (Zot) enconding a new toxin produced by Vibrio cholerae. Infect Immun 1992; 60: 428-434.

11. Waldor MK, Mekalanos JJ. Lysogenic conversion by a filamentous phage encoding cholera toxin. Science 1996; 272: 1910-1914.

12. Levine MM, Kaper JB, Herrington D et al. Volunteers studies of deletion mutants of Vibrio cholerae $\mathrm{O} 1$ prepared by 
recombinant techniques. Infect Immun 1988; 56: 161-167.

13. Tacket CO, Losonsky G, Nataro JP et al. Safety and immunogenicity of live oral cholera vaccine candidate CVD 110, a $\Delta$ ctxA $\Delta$ zot $\Delta$ ace derivative of E1 Tor Ogawa Vibrio cholerae. $J$ Infect Dis 1993; 168: 1536-1540.

14. Levine MM, Kaper JB, Herrington D et al. Safety, immunogenicity, and efficacy of recombinant live oral cholera vaccines CVD 103 and CVD 103-HgR. Lancet 1988; 2: 467-470.

15. Kurazono $\mathrm{H}$, Pal A, Bag PK et al. Distribution of genes encoding cholera toxin, zonula occludens toxin, accessory cholera toxin, and E1 Tor hemolysin in Vibrio cholerae of diverse origins. Microb Pathog 1995; 18: 231-235.

16. Takeda T, Peina Y, Ogawa A et al. Detection of heat-stable enterotoxin in a cholera toxin gene-positive strain of Vibrio cholerae O1. FEMS Microbiol Lett 1991; 80: 23-28.

17. Ramamurthy T, Bag PK, Pal A et al. Virulence patterns of Vibrio cholerae non-Ol strains isolated from hospitalised patients with acute diarrhoea in Calcutta, India. $J$ Med Microbiol 1993; 39: 310-317.

18. Iwanaga $M$, Kuyyakanond $T$. Large production of cholera toxin by Vibrio cholerae $\mathrm{O} 1$ in yeast extract peptone water. $J$ Clin Microbiol 1987; 25: 2314-2316.

19. Oku Y, Uesaka Y, Hirayama T, Takeda Y. Development of a highly sensitive bead-ELISA to detect bacterial protein toxins. Microbiol Immunol 1988; 32: 807-816.

20. Nishibuchi M, Seidler RJ, Rollins DM, Joseph SW. Vibrio factors cause rapid fluid accumulation in suckling mice. Infect Immun 1983; 40: 1083-1091.

21. Shirai H, Nishibuchi M, Ramamurthy T, Bhattacharya SK, Pal SC, Takeda Y. Polymerase chain reaction for detection of the cholera enterotoxin operon of Vibrio cholerae. J Clin Microbiol 1991; 29: 2517-2521.

22. Sun D, Seyer JM, Kovari I, Sumrada RA, Taylor RK. Localization of protective epitopes within the pilin subunit of the Vibrio cholerae toxin-coregulated pilus. Infect Immun 1991; 59: $114-118$

23. Miller VL, Mekalanos JJ. Synthesis of cholera toxin is positively regulated at the transcriptional level by toxR. Proc Natl Acad Sci USA 1984; 81: 3471-3475.

24. Colombo MM, Mastrandrea S, Santona A et al. Distribution of the ace, zot, and ctxA toxin genes in the clinical and environmental Vibrio cholerae. J Infect Dis 1994; 170: 750-751.

25. Iwanaga $M$, Yamamoto $K$. New medium for the production of cholera toxin by Vibrio cholerae $\mathrm{O} 1$ biotype E1 Tor. $J$ Clin Microbiol 1985; 22: 405-408.

26. Finkelstein RA, Atthasampunna P, Chulasamaya M, Charunmethee P. Pathogenesis of experimental cholera: biologic activities of purified procholeragen A. J Immunol 1966; 96 : $440-449$.

27. De SN, Chatterje DN. An experimental study of the mechanism of action of Vibrio cholerae on the intestinal mucous membrane. J Pathol Bacteriol 1953; 66: 559-562.

28. Yuan P, Ogawa A, Ramamurthy $\mathrm{T}$ et al. Vibrio mimicus are the reservoirs of the heat-stable enterotoxin gene (NAG-ST) among species of the gene Vibrio. World J Microbiol Biotechnol 1994; 10: $59-63$.

29. Mukhopadhyay AK, Garg S, Balakrish Nair G et al. Biotype traits and antibiotic susceptibility of Vibrio cholerae serogroup O1 before, during and after the emergence of the 0139 serogroup. Epidemiol Infect 1995; 115: 427-434.

30. Mukhopadhyay AK, Garg S, Mitra R et al. Temporal shifts in traits of Vibrio cholerae isolated from hospitalized patients in Calcultta: a 3-year (1993 to 1995) analysis. J Clin Microbiol 1996; 34: 2537-2543.

31. Saha PK, Koley H, Mukhopadhyay AK et al. Nontoxigenic Vibrio cholerae O1 serotype Inaba biotype E1 Tor associated with a cluster of cases of cholera in Southern India. $J$ Clin Microbiol 1996; 34: 1114-1117.

32. Saha PK, Koley H, Nair GB. Purification and characterization of an extracellular secretogenic non-membrane-damaging cytotoxin produced by clinical strains of Vibrio cholerae non-O1. Infect Immun 1996; 64: 3101-3108.

33. Saha PK, Nair GB. Production of monoclonal antibodies to the non-membrane damaging cytotoxin (NMDCY) purified from Vibrio cholerae $\mathrm{O} 26$ and distribution of NMDCY among strains of Vibrio cholerae and other enteric bacteria using a monoclonal-polyclonal sandwich enzyme-linked immunosorbent assay. Infect Immun 1997; 65: 801-805.

34. Mekalanos JJ. Environmental signals controlling expression of virulence determinants in bacteria. J Bacteriol 1992; 174: 1-7.

35. Baselski V, Briggs R, Parker C. Intestinal fluid accumulation induced by oral challenge with Vibrio cholerae or cholera toxin in infant mice. Infect Immun 1977; 15: 704-712.

36. Holmes RK, Vasil ML, Finkelstein RA. Studies on toxigenesis of Vibrio cholerae. III. Characterization of nontoxigenic mutants in vitro and in experimental animals. $J$ Clin Invest 1974; 55: 551-560.

37. Mekalanos JJ, Mosley SL, Murphy JR, Falkow S. Isolation of enterotoxin structural gene deletion mutations in Vibrio cholerae induced by two mutagenic vibrio phages. Proc Natl Acad Sci USA 1982; 79: 151-155.

38. Pierce NF, Kaper JB, Mekalaos JJ, Cray WC. Role of cholera toxin in enteric colonization by Vibrio cholerae $\mathrm{O} 1$ in rabbits Infect Immun 1985; 50: 813-816. 